Research Article

\title{
An Epidemiological Study on Risk Factors of Chronic Obstructive Pulmonary Disease
}

\author{
Pratima Gedam', Jugal Kishore ${ }^{2}, \underline{\text { Heena }}^{3},{\text { Pranav } 1 \mathrm{sh}^{4}}^{4} \underline{\text { Meena Sehgal }}^{5}$
}

${ }^{1}$ Assistant Professor, ${ }^{2}$ Director Professor and Head, ${ }^{3}$ Statistician, Department of Community Medicine, VMMC \& Safdarjung Hospital, New Delhi, India.

${ }^{4}$ Assistant Professor, Department of Pulmonary, Critical Care and Sleep Medicine, VMMC and Safdarjung Hospital, New Delhi, India.

${ }^{5}$ Fellow, The Energy and Resources Institute (TERI), Darbari Seth Block IHC Complex, Lodhi Road, New Delhi, India.

DOI: https://doi.org/10.24321/2455.7048.202104

\section{I $\quad \mathbf{N} \quad \mathbf{F} \quad \mathbf{O}$}

\section{Corresponding Author:}

Pranav Ish, Department of Pulmonary, Critical Care and Sleep Medicine, VMMC and Safdarjung Hospital, New Delhi-110016, India

E-mail Id:

pranavish2512@gmail.com

Orcid Id:

https://orcid.org/0000-0003-1701-4970

How to cite this article:

Gedam P, Kishore J, Heena, Ish P, Sehgal M. An Epidemiological Study on Risk Factors of Chronic Obstructive Pulmonary Disease. Epidem Int. 2021;6(1):15-21.

Date of Submission: 2021-02-26

Date of Acceptance: 2021-03-24

\section{$\begin{array}{llllllll}\mathbf{A} & \mathbf{B} & \mathbf{S} & \mathbf{T} & \mathbf{R} & \mathbf{A} & \mathbf{C} & \mathbf{T}\end{array}$}

Introduction: Chronic Obstructive Pulmonary Disease (COPD) is one of the leading causes of morbidity and mortality worldwide and is expected to increase in the coming decades due to increasing air pollution. In a country like India, it is a challenge to control the growing incidence of COPD. For this, it is imperative to understand the various risk factors that lead to the development of COPD including smoking and the everworsening environmental air pollution levels.

Material and Methods: This prospective case-control study was carried out at the out-patient clinic of pulmonary medicine at our tertiary care centre. Clinical severity data, demographic characteristics, smoking history, and particulate matter (PM) 2.5 levels at the residence of the patients were recorded. A total of 182 cases of COPD and 365 controls were taken.

Result: COPD was found to be common among males (69.2\%), among the factory workers, drivers and roadside vendors and in elderly age groups. COPD was found to be associated with exposure to active and passive smoking $(p<0.05)$. Exposure to dust, fumes, and smoke at the workplace was significantly more prevalent among the COPD patients (13.2\%) than the control group (2.7\%). Besides, $61.5 \%$ of the COPD patients were residing in the area with PM 2.5 levels $>60 \mu \mathrm{g} / \mathrm{m} 3$ which was significantly greater than the controls (44.9\%).

Conclusion: The main risk factor for COPD is exposure to active and passive tobacco smoking. Other environmental factors such as exposure to dust, fumes at the workplace and home are also associated with COPD. Level of PM $2.5>60 \mu \mathrm{g} / \mathrm{m} 3$ is associated with an increased risk of COPD. Thus, the environmental history of residence in Delhi or a city with high AQI is significant in evaluating a COPD patient. It is important to understand the contribution of these risk factors as curbing and curtailing them can help prevent and control the growing burden of COPD.

Keywords: COPD, Risk Factors, Air Pollution, PM 2.5, Lung Disease 


\section{Introduction}

Chronic obstructive pulmonary disease (COPD) is a progressive life-threatening lung disease that causes breathlessness and predisposes to exacerbations and serious illness. It is one of the leading causes of morbidity and mortality worldwide and is expected to increase in the coming decades. The development of COPD usually takes several decades. It is an irreversible condition associated with progressive airflow limitation, with symptoms of cough, dyspnoea, and sputum. ${ }^{1}$ The prevalence of COPD of any stage in adults rises from $1 \%$ in the general population to $9 \%-10 \%$ in people aged $\geq$ 40 years, but the fact that many stage I patients may be asymptomatic or present with signs that are not perceived as abnormal suggests that global and national estimates could be underestimated. ${ }^{2}$

The Global Burden of Disease Study reports a prevalence of 251 million cases of COPD globally in 2016. Globally, it is estimated that 3.17 million deaths were caused by the disease in 2015 (that is, $5 \%$ of all deaths in that year). More than $90 \%$ of COPD deaths occur in low and middle-income countries worldwide. ${ }^{3}$ Chronic Obstructive Pulmonary Disease (COPD) is the 4th largest cause of death in the world. According to the World Health Organization, COPD kills more people than HIV-AIDS, malaria, and tuberculosis combined in the South East Asian region. According to a report published by the National Centre for Macroeconomics and Health, it was estimated that the economic loss due to COPD in India is around Rs 35,000 crores. $^{4}$

The contribution of chronic respiratory diseases to the total disability-adjusted life years (DALYs) in India increased from $4.5 \%$ in 1990 to $6.4 \%$ in 2016 . The number of cases of COPD in India increased from 28.1 million in 1990 to 55.3 million in 2016 , an increase in prevalence from $3.3 \%$ to $4.2 \%$. The crude prevalence was highest in the contiguous north Indian states of Jammu and Kashmir, Himachal Pradesh, Uttarakhand, Haryana, and Delhi. The next highest COPD prevalence values were in Rajasthan, Uttar Pradesh, and Punjab in the north, Mizoram in the northeast, and Maharashtra, Goa, Kerala, Karnataka, Andhra Pradesh, and Telangana in the west and south of India. ${ }^{5}$

The DALYs per case of COPD and asthma were 1.7 and 2.4 times higher in India than the global average in 2016, respectively; most states had higher rates compared with other locations worldwide at similar levels of sociodemographic index. Of the DALYs due to COPD in India in 2016, $53.7 \%$ were attributable to air pollution, $25.4 \%$ to tobacco use, and $16.5 \%$ to occupational risks, making these the leading risk factors for COPD. ${ }^{5}$

However, there is dearth of studies from India documenting the burden of disease estimation for COPD. Several studies have concluded that COPD distribution greatly differs across geographical disparities. However, heterogeneity may not be solely geographical and could be due to underlying differences in socioeconomic status, racial and ethnic dissimilarities. Keeping all this in mind, the present study was undertaken to understand the role of risk factors such as tobacco smoking, biomass fuel combustion, and other environmental exposures for the occurrence of COPD. ${ }^{6}$

\section{Methods}

\section{Study Setting}

The present case-control study was carried out at the outpatient clinic of the pulmonary medicine department of Safdarjung hospital, New Delhi, India for one and a half years with the objective to determine the risk factors associated with the occurrence of COPD.

\section{Inclusion Criteria}

The whole study population was composed of nonhospitalized individuals. The cases include diagnosed outpatient cases of COPD which were diagnosed by using post bronchodilator FEV1/ FVC ratio $<0.7 .{ }^{7}$ Airflow limitation in COPD is classified based on post bronchodilator FEV1 value into four groups (Grade 1 to 4 ) using criteria suggested by the GOLD (Global Initiative for COPD) committee. ${ }^{8}$ Inclusion criteria for choosing controls was that they should be free of COPD or any other respiratory disease (no asthma, no lung cancer, no lung fibrosis) with no complaints of any chronic respiratory symptom (no chronic cough, no chronic sputum production, no wheezing, no dyspnoea at rest or on exertion).

\section{Exclusion Criteria}

Obstetric, psychiatric, and hospitalised cases were excluded from our study.

\section{Sample Size}

As per previous studies, the factor that is significantly associated with COPD is smoking (OR $=4.54)$. Using this odds ratio, the minimum required sample size with $80 \%$ power of study and $5 \%$ level of significance was calculated, which came to 73 .

\section{Informed Consent}

Written informed consent was taken from all the patients.

\section{Ethical Clearance}

Ethical clearance was taken from the Institutional Ethics Committee.

\section{Data Collection}

After obtaining informed consent from each participant, a detailed history of patient was taken in pre-structured pro forma. The variables used for analysis included age, gender, usual place of residence, education, occupation, socio-economic class, food habits, duration of stay at Delhi, and history of active and passive smoking etc. A smoker was defined by the presence of regular smoking of any type 
for one year or more. Exposure to environmental tobacco smoke was also evaluated. We have collected data on the air quality of the area, where participants were residing. Data on air quality index and level of PM 2.5 \& PM 10 were collected from the state air pollution website link (https:// aqicn.org/city/delhi). The readings were collected for the same day as the patient came to the hospital and he/she was interviewed for his symptoms.

\section{Statistical Analysis}

The statistical analysis was performed using SPSS software. Continuous variables were expressed as mean \pm standard deviation and categorical variables as frequencies. The associations between categorical variables were tested using chi-square test. Odds ratios were calculated to obtain the strength of association. An unconditioned multivariate logistic regression model was used to obtain the association between exposures and COPD, after adjusting for potential confounders. A test was considered statistically significant when $p<0.05$.

\section{Result}

The present study included 182 cases of COPD and 365 controls. The mean age of the male patients of COPD was $46.5 \pm 12.89$ years and among female patients, it was $40.59 \pm 12.24$ years. Our study shows that there is an increase in the prevalence of COPD with the increasing age of the patient and the trend was found to be statistically significant $(p<0.05)$. COPD was more common among males (male:female ratio among cases was 2.25:1). COPD was also found to be more common among participants educated up to high schools $(75.3 \%)$ as compared to the participants who were graduate and had professional degrees (24.7\%). The maximum number of cases were from the upper middle class (Table 1 ). Out of the total COPD cases, $69.8 \%$ cases were moderate, $22 \%$ were mild, and $7.1 \%$ severe, and $1.1 \%$ cases were very severe as shown in Figure 1. The most common symptoms included dry cough, cough with sputum, breathlessness, easy fatigability, and wheeze (Figure 2).

Table I.Socio-demographic Characteristics of Cases of COPD and Controls

\begin{tabular}{|c|c|c|c|c|}
\hline \multirow{2}{*}{ Variable } & \multicolumn{2}{|c|}{ Final Diagnosis } & \multirow{2}{*}{$\begin{array}{l}\text { Chi-square } \\
\text { for Trend }\end{array}$} & \multirow{2}{*}{$p$ value } \\
\hline & COPD Cases $(n=182)$ & CONTROL $(n=365)$ & & \\
\hline \multicolumn{5}{|l|}{ Age (years) } \\
\hline$<40(n=241)$ & $62(34.1)^{*}$ & $179(49.0)^{*}$ & 1 & \multirow{3}{*}{0.001} \\
\hline $40-60(n=275)$ & $100(54.9)$ & $175(47.9)$ & 1.65 & \\
\hline$>60(n=31)$ & $20(11.0)^{*}$ & $11(3.0)^{*}$ & 5.25 & \\
\hline \multicolumn{5}{|l|}{ Gender } \\
\hline Male $(n=343)$ & $126(69.2)$ & $217(59.5)$ & \multirow{2}{*}{4.966} & \multirow{2}{*}{0.026} \\
\hline Female $(n=204)$ & $56(30.8)$ & $148(40.5)$ & & \\
\hline \multicolumn{5}{|l|}{ Education } \\
\hline Graduate and post graduate $(n=179)$ & $45(24.7)$ & $134(36.7)$ & \multirow{2}{*}{7.926} & \multirow{2}{*}{0.005} \\
\hline Up to high school $(n=368)$ & $137(75.3)$ & $231(63.3)$ & & \\
\hline \multicolumn{5}{|l|}{ Occupation } \\
\hline Housewife $(n=174)$ & $49(26.9)$ & $125(34.2)$ & \multirow{3}{*}{19.038} & \multirow{3}{*}{0.001} \\
\hline Driver, factory worker, road side vendor $(n=65)$ & $37(20.3)^{*}$ & $28(7.7)^{*}$ & & \\
\hline $\begin{array}{l}\text { Student, teacher, office job, police, business, } \\
\text { others }(n=308)\end{array}$ & $96(52.7)$ & $212(58.1)$ & & \\
\hline \multicolumn{5}{|l|}{ Socio-economic Class } \\
\hline Upper class $(n=16)$ & $8(4.4)$ & $8(2.2)$ & \multirow{3}{*}{3.363} & \multirow{3}{*}{0.186} \\
\hline Upper middle class $(n=386)$ & $121(66.5)$ & $265(72.6)$ & & \\
\hline Lower middle class $(n=145)$ & $53(29.1)$ & $92(25.2)$ & & \\
\hline \multicolumn{5}{|l|}{ BMI } \\
\hline Obese $(n=6)$ & $1(0.5)$ & $5(1.4)$ & \multirow{4}{*}{12.177} & \multirow{4}{*}{0.007} \\
\hline Overweight $(n=171)$ & $40(22.0)^{*}$ & $131(35.9)^{*}$ & & \\
\hline Normal $(n=359)$ & $137(75.3)^{*}$ & $222(60.8)^{*}$ & & \\
\hline Underweight $(n=11)$ & $4(2.2)$ & $7(1.9)$ & & \\
\hline
\end{tabular}

Note: * Statistical significant in $2 \times 2$. 
Table 2.Distribution of Study Participants as History of Active and Passive Smoking and Air Pollution at Workplace and Residence

\begin{tabular}{|c|c|c|c|c|c|c|}
\hline \multirow[b]{2}{*}{ Variable } & \multicolumn{2}{|c|}{ Final Diagnosis } & \multirow[b]{2}{*}{ Odds Ratio } & \multicolumn{2}{|c|}{ 95\% Confidence Interval } & \multirow[b]{2}{*}{$p$ value } \\
\hline & $\begin{array}{c}\text { COPD } \\
(n=182)\end{array}$ & $\begin{array}{l}\text { CONTROL } \\
(n=365)\end{array}$ & & Lower & Upper & \\
\hline \multicolumn{7}{|c|}{ Tobacco smoking } \\
\hline $\operatorname{Yes}(n=81)$ & $53(29.1)$ & $28(7.7)$ & \multirow{2}{*}{4.945} & \multirow{2}{*}{2.997} & \multirow{2}{*}{8.16} & \multirow{2}{*}{0.001} \\
\hline No $(n=466)$ & $129(70.9)$ & $337(92.3)$ & & & & \\
\hline \multicolumn{7}{|c|}{ Presently smoking } \\
\hline Yes $(n=53)$ & $40(22.0)$ & $13(3.6)$ & \multirow{2}{*}{7.627} & \multirow{2}{*}{3.961} & \multirow{2}{*}{14.689} & \multirow{2}{*}{0.001} \\
\hline No $(n=494)$ & $142(78.0)$ & $352(96.4)$ & & & & \\
\hline \multicolumn{7}{|c|}{ Does anyone smoke at home? } \\
\hline Yes $(n=40)$ & 35 (19.2) & $5(1.4)$ & \multirow{2}{*}{17.143} & \multirow{2}{*}{6.587} & \multirow{2}{*}{44.615} & \multirow{2}{*}{0.000} \\
\hline No $(n=507)$ & $147(80.8)$ & $360(98.6)$ & & & & \\
\hline \multicolumn{7}{|c|}{$\begin{array}{c}\text { Does anyone smoke at } \\
\text { workplace? }\end{array}$} \\
\hline Yes (n = 39) & $34(18.7)$ & $5(1.4)$ & \multirow{2}{*}{16.541} & \multirow{2}{*}{6.345} & \multirow{2}{*}{43.116} & \multirow{2}{*}{0.000} \\
\hline No $(n=508)$ & $148(81.3)$ & $360(98.6)$ & & & & \\
\hline \multicolumn{7}{|c|}{$\begin{array}{l}\text { Is there any dust smoke fume } \\
\text { exposure at workplace? }\end{array}$} \\
\hline Yes $(n=34)$ & $24(13.2)$ & $10(2.7)$ & \multirow{2}{*}{5.392} & \multirow{2}{*}{2.519} & \multirow{2}{*}{11.544} & \multirow{2}{*}{0.000} \\
\hline No $(n=513)$ & $158(86.8)$ & $355(97.3)$ & & & & \\
\hline \multicolumn{7}{|c|}{$\begin{array}{l}\text { Is there any family history of } \\
\text { COPD present? }\end{array}$} \\
\hline Yes $(n=480)$ & $162(89.0)$ & $318(87.1)$ & \multirow{2}{*}{1.197} & \multirow{2}{*}{0.686} & \multirow{2}{*}{2.088} & \multirow{2}{*}{0.526} \\
\hline No $(n=67)$ & $20(11.0)$ & $47(12.9)$ & & & & \\
\hline
\end{tabular}

Table 3.Distribution of Study Participants as per Exposure to Level of PM 2.5

\begin{tabular}{|c|c|c|c|c|c|c|}
\hline \multirow{2}{*}{$\begin{array}{c}\text { Level of PM } 2.5 \text { at Residential } \\
\text { Address }\end{array}$} & \multicolumn{2}{|c|}{ Final Diagnosis } & \multirow{2}{*}{$\begin{array}{l}\text { Chi- } \\
\text { square }\end{array}$} & \multicolumn{2}{|c|}{ 95\% Confidence Interval } & \multirow[b]{2}{*}{$p$ value } \\
\hline & $\begin{array}{c}\text { COPD } \\
(n=182)\end{array}$ & $\begin{array}{l}\text { CONTROL } \\
(n=365)\end{array}$ & & Lower & Upper & \\
\hline Good and Satisfactory $(n=271)$ & $70(38.5)$ & $201(55.1)$ & 13.39 & 0.355 & 0.733 & 0.001 \\
\hline $\begin{array}{c}\text { Moderate, poor, very poor and } \\
\text { severe }(n=276)\end{array}$ & $112(61.5)$ & 164 (44.9) & & & & \\
\hline
\end{tabular}

Table 4.Distribution of Non-smoker Study Participants as per Different Levels of PM 2.5

\begin{tabular}{|c|c|c|c|c|}
\hline \multirow{2}{*}{ PM 2.5} & \multicolumn{2}{|c|}{ Non-smoker } & \multirow{2}{*}{ Chi-square } & \multirow{2}{*}{$p$ value } \\
\hline & $\operatorname{COPD}(n=142)$ & CONTROL $(n=352)$ & & \\
\hline Good and satisfactory $(n=244)$ & $52(36.6)$ & $192(54.5)$ & 13.007 & 0.001 \\
\hline $\begin{array}{c}\text { Moderate, poor, very poor and } \\
\text { severe }(n=250)\end{array}$ & $90(63.4)$ & $160(45.5)$ & & \\
\hline
\end{tabular}

Most cases (63.7\%) and control (69\%) were residing in Delhi for $11-20$ years. There is no statistically significant association between the causation of COPD and the duration of stay inside Delhi. There was no statistically significant association between the occurrences of COPD with time spent outside home (Table 1). The maximum number of cases of COPD were from South Delhi (39.6\%) followed by West Delhi (24.2\%). This data is not shown in table. 
Table 5.Predictors of COPD by Multivariate Logistic Regression

\begin{tabular}{|c|c|c|c|c|c|c|c|c|}
\hline \multirow{2}{*}{ Variables in the Equation } & \multirow{2}{*}{ B } & \multirow{2}{*}{ S.E. } & \multirow{2}{*}{ Wald } & \multirow{2}{*}{ df } & \multirow{2}{*}{ Sig. } & \multirow{2}{*}{ Exp (B) } & \multicolumn{3}{|c|}{$95 \% \mathrm{Cl}$} \\
\cline { 8 - 10 } & & & & & & & Lower & Upper \\
\hline Age & -0.027 & 0.01 & 8.083 & 1 & 0.004 & 0.973 & 0.955 & 0.992 \\
\hline Sex & 0.446 & 0.386 & 1.336 & 1 & 0.248 & 1.561 & 0.733 & 3.324 \\
\hline Education & -0.243 & 0.252 & 0.929 & 1 & 0.335 & 0.784 & 0.479 & 1.286 \\
\hline Occupation & 0.219 & 0.2 & 1.195 & 1 & 0.274 & 1.245 & 0.841 & 1.844 \\
\hline District & -0.001 & 0.09 & 0 & 1 & 0.989 & 0.999 & 0.838 & 1.191 \\
\hline H/o Tobacco smoking & 1.377 & 0.296 & 21.651 & 1 & 0.001 & 3.964 & 2.219 & 7.081 \\
\hline $\begin{array}{c}\text { H/o Exposure to dust, smoke } \\
\text { and fumes at work }\end{array}$ & 1.401 & 0.432 & 10.495 & 1 & 0.001 & 4.06 & 1.739 & 9.476 \\
\hline BMI & 0.782 & 0.21 & 13.908 & 1 & 0.001 & 2.185 & 1.449 & 3.296 \\
\hline PM 2.5 & -0.004 & 0.001 & 19.221 & 1 & 0.001 & 0.996 & 0.994 & 0.998 \\
\hline Constant & -5.452 & 1.634 & 11.139 & 1 & 0.001 & 0.004 & & \\
\hline
\end{tabular}

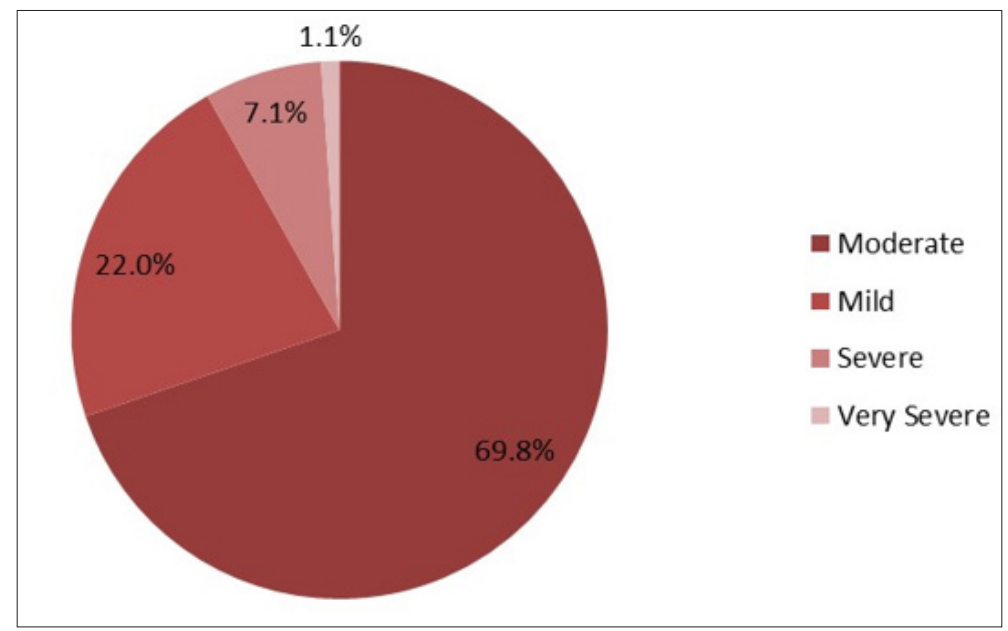

Figure I.Distribution of Cases of COPD as per Severity

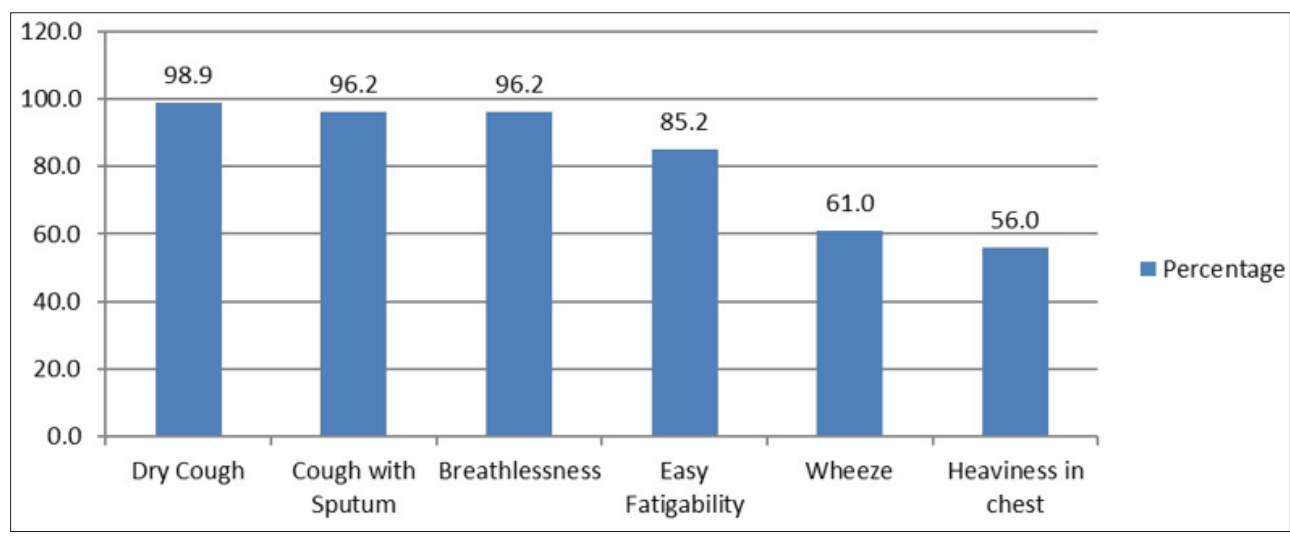

Figure 2.Distribution of Symptoms among the Patients of COPD

COPD was found to be strongly associated with active and passive smoking, as $22 \%$ of the participants among cases were current smokers as compared to $3 \%$ of the participants among controls. This difference was found to be statistically significant. Current exposure to passive smoking at home (19.2\%) and workplace (18.7\%) was more prevalent among COPD patients than control (1.4\% each) subjects, with a statistically significant difference between cases and controls. Exposure to dust, fumes, and smoke at the workplace was significantly more prevalent 
among COPD patients (13.2\%) than the control (2.7\%) group (Table 2). Among the COPD group, $61.5 \%$ were residing in the area with PM 2.5 levels $>60 \mu \mathrm{g} / \mathrm{m} 3$ as compared to $44.9 \%$ controls, which was statistically significant (Table 3). Further, among non-smoker COPD, a similar difference was observed, which was statistically significant (Table 4).

Table 5, shows the multivariate logistic regression for factors predicting COPD in the study. The final retained model suggested that age, tobacco smoking, and BMI are independent risk factors for COPD.

\section{Discussion}

Our study identified male preponderance in the occurrence of COPD (69.2\%). Multiple risk factors in India are responsible for this including prevalent addiction to smoking, increased exposure to environmental pollution at work as well as during travelling. This is consistent with other studies that reported that COPD is distinctly more common amongst men. ${ }^{1,10}$ COPD was found to be less prevalent among people under 40 years of age. The proportion of COPD sufferers showed an incremental increase in prevalence with increasing age, reaching a peak in those aged 60-69 years. Generally, age above 40 years is considered as a risk factor for COPD, as normally addiction to smoking begins in adolescence, and it would take 20-25 years of exposure to tobacco smoke to induce characteristic pathophysiologic changes of COPD in human lungs. Similar observations have been recorded from studies across India. ${ }^{1,4,9,10}$

COPD was less prevalent among the participants who were graduate and professionals as compared to less educated participants possibly due to indoor occupations. ${ }^{11,12}$ COPD was more prevalent among drivers, factory workers, and roadside vendors as compared to students, teachers, and homemakers; these participants are more exposed to environmental air pollution and fumes and dust at workplace than the other group. These findings are similar to other studies. ${ }^{10,14}$ We could not find any statistical association between COPD and food habits of the participants, similar to previous literature.11 $\mathrm{BMI}$ is an important prognostic factor and is included in the BODE index. We also documented that mean BMI was reduced in subjects with COPD consistent with similar studies in the past. ${ }^{11,13}$

In our study, $29.1 \%$ of COPD patients were having a history of smoking and $22 \%$ of COPD cases were current smokers. Exposure to environmental tobacco smoke by passive smoking at home and at workplace was also significantly higher. Thus, active and passive smoking, and environmental smoke exposure are all important components of environmental and occupational evaluation of a COPD patient. ${ }^{10,12}$

When checked for $A Q \mathrm{I}$ at the residential address of participants, we found that $63.3 \%$ of the cases of COPD are from the area where the level of PM 2.5 is $>60 \mu \mathrm{g} /$ m3; especially among non-smoking COPD who had no evident risk factor for COPD. This cut-off is the breakpoint concentration as per the National air quality index guidelines of the National Pollution Control Board in India. Similar studies from across the globe stress upon the importance of air pollution as an independent risk factor for the development of COPD. ${ }^{13-17}$ This finding supports the importance of environmental evaluation as a part of risk factor assessment for COPD. Even though smoking (both active and passive) is the major contributor, air pollution is an often ignored and underestimated risk factor for the development of COPD.

Understanding geographic variations in COPD hospitalisation could help public health policymakers to identify target areas with greater needs more clearly and facilitate better solutions to improve COPD prevention and treatment strategies. In a resource-poor country like India, it is a challenge to curb the rising cases of COPD. Therefore, the prevention of the development of COPD becomes the most promising option to reduce the burden of COPD. This involves smoking cessation and improving environmental air pollution. Several government initiatives have been launched in the past few years to reduce air pollution. This includes guidelines for the reduction in particulate matter emissions by coal power plants, reduction in energy consumption by energy-intensive industries, $40 \%$ of the electricity production from a renewable source is planned by 2030, management of agricultural stubble burning, vehicle emissions regulation, and upgrading of vehicles to more fuel-efficient standards. ${ }^{18}$ However, most of these schemes have had a limited impact and face long term challenges. The main risk factor for COPD is exposure to active and passive tobacco smoking, environmental factors such as exposure to dust, fumes at workplace and home which is also reported by other authors. ${ }^{19}$

\section{Conclusion}

The study concludes that major risk factors for COPD are exposure to active and passive tobacco smoking, the high level of PM 2.5, environmental factors such as exposure to dust, fumes at workplace and home. Therefore, Delhi needs program for curbing and curtailing these risk factors, which can decrease the prevalence of COPD.

\section{Source of Funding}

No funding support was taken for the conduct of the study.

\section{Conflict of Interest: None}

\section{References}

1. Stephen P, Mahalakshmy T, Manju R, Laksham KB, Subramani S, Panda K, Sarkar S. High Prevalence of Chronic Respiratory Symptoms among Autorickshaw 
Drivers of Urban Puducherry, South India. Indian J Occup Environ Med. 2018;22(1):40-44. [PubMed] [Google Scholar]

2. Mathers CD, Loncar D. Projections of global mortality and burden of disease from 2002 to 2030. PLoS Med. 2006;3(11):e442. [PubMed] [Google Scholar]

3. World Health Organization [Internet]. Burden of COPD. [cited 2021 Mar 14]. Available from: https://www.who. int/respiratory/copd/burden.

4. Meghwani MK, Tiwari HC, Mishra R, Kumar S. Chronic obstructive pulmonary disease and its risk factors: a case control study. J Evol Med Dent Sci. 2013;2(34);6382-6. [Google Scholar]

5. India State-Level Disease Burden Initiative CRD Collaborators. The burden of chronic respiratory diseases and their heterogeneity across the states of India: the Global Burden of Disease Study 1990-2016. Lancet Glob Health. 2018;6(12):e1363-74. [PubMed] [Google Scholar]

6. Sharma AK, Kalra OP, Saini NK, Kelkar H. Pilot Study of Chronic Obstructive Pulmonary Disease in an Industrial Town in India. J Health Pollut. 2019;9(21):190304. [PubMed] [Google Scholar]

7. Mannino DM, Holguin F. Epidemiology \& Global Impact of COPD. Respiratory Medicine: COPD Update. 2006;1:114-20. [Google Scholar]

8. Global Initiative for COPD [Internet]. Pocket guide to COPD Diagnosis, Management and Prevention, 2017 report. [cited 2021 Mar 14]. Available from: https:// goldcopd.org/wp-content/uploads/2016/12/wmsGOLD-2017-Pocket-Guide.pdf.

9. Madhurmay, Suryakant, Kumar H, Kumar S, Prasad $\mathrm{R}$, Verma AK, Singh AK. Study of association between exposure to indoor air pollution and chronic obstructive pulmonary disease among nonsmokers in a North Indian population - A case-control study. Indian J Respir Care. 2019;8:71-5. [Google Scholar]

10. Pandey R, Pandey S. A case control study in BMC Sagar to assess the risk factors of COPD. Int J Adv Med. 2017;4(4):1155-7.

11. Woldeamanuel GG, Mingude AB, Geta TG. Prevalence of chronic obstructive pulmonary disease (COPD) and its associated factors among adults in Abeshge District, Ethiopia: a cross sectional study. BMC Pulm Med. 2019;19(1):181. [PubMed] [Google Scholar]

12. Magitta NF, Walker RW, Apte KK, Shimwela MD, Mwaiselage JD, Sanga AA, Namdeo AK, Madas SJ, Salvi SS. Prevalence, Risk factors, and clinical correlates of COPD in a rural setting in Tanzania. Eur Respir J. 2018;51:1700182. [PubMed] [Google Scholar]

13. Çolak Y, Afzal S, Nordestgaard BG, Vestbo J, Lange P. Prevalence, Characteristics, and Prognosis of Early Chronic Obstructive Pulmonary Disease. The
Copenhagen General Population Study. Am J Respir Crit Care Med. 2020 Mar 15;201(6):671-80. [PubMed] [Google Scholar]

14. Dement J, Welch L, Ringen K, Quinn P, Chen A, Haas S. A case-control study of airways obstruction among construction workers. Am J Ind Med. 2015 Oct;58(10):1083-97. [PubMed] [Google Scholar]

15. De Oliveira BFA, Ignotti E, Artaxo P, Saldiva PHN, Junger WL, Hacon S. Risk assessment of PM (2.5) to child residents in Brazilian Amazon region with biofuel production. Environ Health. 2012;11:64. [PubMed] [Google Scholar]

16. Schwartz J. Harvesting and long-term exposure effects in the relation between air pollution and mortality. Am J Epidemiol. 2000;151:440-8. [PubMed] [Google Scholar]

17. Franklin $M$, Koutrakis $P$, Schwartz $P$. The role of particle composition on the association between PM2.5 and mortality. Epidemiology. 2008;19:680-9. [PubMed] [Google Scholar]

18. International Energy Policy [Internet]. India 2020: Energy Policy Review. Available from: https://niti.gov. in/sites/default/files/2020-01/IEA-India\%202020-Indepth-EnergyPolicy_0.pdf

19. Gupta N, Agrawal S, Chakrabarti S, Ish P. COPD 2020 Guidelines - what is new and why? Adv Respir Med. 2020;88(1):38-40. [PubMed] [Google Scholar] 